\title{
INFORMATION-FLOW-BASED SAFETY EDUCATION (IFSE): AN INDISPENSABLE PERSPECTIVE ON SAFETY EDUCATION
}

\author{
Kaixin GAO ${ }^{\circledR}$, Keping ZHOU ${ }^{\mathbb{D}}$, Zhipeng LIANG ${ }^{\circledR}{ }^{*}$ \\ School of Resources and Safety Engineering, Central South University, \\ Changsha 410083, Hunan, The People's Republic of China
}

Received 29 May 2020; accepted 10 May 2021

\begin{abstract}
Any systems can be expressed by and connected with information. For the safety education system, doing so is essentially a process of safety information dissemination and cognition. Therefore, information is the core of the safety education system. At present, the key factors affecting the effectiveness of safety education are safety demand analysis information, the dissemination and cognitive processes of safety information and information feedback. Research on the construction of a framework model for safety education under the guidance of information flow clears and classifies information-related elements of the safety education process. Therefore, it is conducive to the construction of a safety education system to improve its management level and, through the rational use of information technology, to improve the conversion rate of safety information into safety behaviour. Based on a systematic review and comparison of the existing research perspectives on safety education and information-flow-based safety education (IFSE), this paper analyses the reasons why we need a new perspective on safety education. We introduce information flow into the safety education framework model. The fundamental and expanding elements of safety education propagation are examined and deduced based on information theory. Combined with the connotations of safety education and information flow, this paper analyses the implementation steps of IFSE and applies them to the safety education of new employees in metal and nonmetal mines. In the micro-design, virtual reality technology is used to integrate safety education content and information technology. A new perspective on safety education is created; then, the framework model of IFSE, its implementation steps and models of the processing and utilization processes of safety education are constructed. IFSE is a new perspective for realizing safety education in practice, and the framework model of IFSE provides rigorous theoretical knowledge. Of course, to improve IFSE in practice, more scientific and detailed evaluation methods need to be introduced. This paper is helpful for guiding the safety education theory research from "trivializes situated" to "systematic" and for guiding the design, implementation, assessment and optimization of the safety education practice.
\end{abstract}

Keywords: information cognition, information dissemination, safety education, framework model, system, virtual reality.

\section{Introduction}

\section{Research status of safety management and safety education}

Accidents happen every day in the world, and unsafe behaviour is an important reason for a series of unsafe events, including accidents, injuries, losses and network safety events (Heinrich, 1980; Mcsween, 1995; Han \& Lee, 2013; Li et al., 2015). In the past 20 years, behaviourbased and cognition-based safety management have been researched hotspots and difficulties. Application of this type of safety management involves many fields, including the mining (Liu \& Song, 2014), construction (Mitropoulos et al., 2009; Zhou et al., 2008), petrochemical industries (Songkhla et al., 2018; Zohar \& Luria, 2003), transportation (Glendon \& Litherland, 2001), aerospace (Gore, 2002), etc. Especially in China, since enterprise safety standardization was established in 2011, the number of deaths from accidents has decreased significantly. Since 2014, the number of deaths from accidents has not decreased significantly. Safety bottlenecks have been encountered in Chinese safety production. Thus, more effective measures should be taken in the management of human safety behaviour (including safety psychology). As the ultimate goal of safety education is to improve safety behaviour and cognition, safety education is the basis of behaviour-based safety management, which plays an equally important role with enforcement- and safety engineering-based safety management (Zhong, 2013). Therefore, research on the flow process from safety information

*Corresponding author. E-mail: 391145637@qq.com

Copyright (C) 2021 The Author(s). Published by Vilnius Gediminas Technical University

This is an Open Access article distributed under the terms of the Creative Commons Attribution License (http://creativecommons.org/licenses/by/4.0/), which permits unrestricted use, distribution, and reproduction in any medium, provided the original author and source are credited. 
into safety behaviours provides a new research idea for safety education.

Currently, research on the application of safety education and training in high-risk industries and of new information technology is common (Le et al., 2015; Wang et al., 2018; Zhang et al., 2017); however, it lacks a foundation in the perspective on systems and information, so it is difficult to make a breakthrough in macro-control, management and lifelong safety education and there is a lack of scientific guidelines in micro-practice. Because of information explosion, research on safety education cannot focus only on the process of safety information transmission but must also identify effectively useful safety information, which is a solid foundation for safety education (Limberg \& Sundin, 2006). According to the survey, some problems remain to be urgently solved. For example, many designs of safety education and training are based on intuition and lack a systematic analysis; therefore, they instead mostly adopt a rough management. Additionally, the teaching content of safety education is too rigid, chaotic, unsystematic, and of weak pertinence while inculcating more knowledge and less cognitive inspiration. In general, it is not only difficult to ensure the effectiveness of safety education but also to prove its positive impact; moreover, some safety trainings may even create a negative psychology in their participants.

\section{Research status of information-based behaviour model}

The advantages of the information age are that academia has come to realize that information controls human behaviour. As a general research object, information provides a new perspective for understanding, changing and optimizing safety education (Lei et al., 2019; Catino \& Patriotta, 2013; Kostopoulou, 2006; Wang et al., 2017). Research on safety information cognition, behaviour and information management systems has been extended to many industries (Njenga \& Brown, 2012; Chaudhry et al., 2011), and its application is basically mature. Some classic behavioural models have been developed based on information, such as the information-decision-action model (Mosleh \& Chang, 2004) and the information-motivationbehaviour skills model (Misovich et al., 2006). The cherry model partially reveals the mechanism of the impact of safety information on human safety behaviour (Sklet, 2004), and safety information should be an excellent entry point for safety behaviour management.

\section{The research route of this paper}

After lengthy research on, exploration of and thinking about safety information, behaviour and education, we finally positioned the practice process of IFSE. Generally, a good model of a scientific field can effectively guide all research and practice. In this respect, this paper attempts to construct a new model of safety education based on information flow to provide a basis for the theory and practice of systematic safety education, its basic ideas and methods and then to enhance the effectiveness of safety education.
Starting from the demand analysis, design, implementation, evaluation, feedback and other behaviours of safety education, this paper explains the information flow and implementation steps involved in the practice of safety education in detail, and a process model is constructed for information processing and utilization of IFSE centred on the educated to improve and optimize the practice of safety education.

\section{Why is it necessary to research IFSE?}

Essentially and theoretically, safety education is a dynamic process of information transmission and cognition through the cooperation of various elements between the educated and the educators, and safety information must be sublimated into safety behaviour through the processing and appreciation of the human subject's thinking. From a systematic point of view, if each element is regarded as a subsystem, then information is the key to communication between subsystems. What follows are the reasons for researching IFSE:

1. Safety education is a branch of safety science. Under the premise of basic education, safety education is an integrated activity in the face of complex cognition with the purpose of standardizing and improving safety behaviours. In recent years, safety science has made progress in the aspects of safety demand analysis, safety information management and human factor accidents. The achievements of safety science should be fully absorbed in the practice of safety education. From the perspective of safety education design, research on IFSE can effectively improve the quality of safety education.

2. Safety education is a branch of education, which is essentially the process of information dissemination and cognition. Information theory, cybernetics and system theory are at the root of educational theory. Especially for educational activities aimed at training complex cognitive skills, information-processing theory, situational cognitive theory and constructivism theory are their theoretical bases. The pedagogical research in the training of complex cognitive skills can provide some valuable implications for safety education.

3. Safety education has strong practicability. However, a major, long-standing and common problem in safety education is how to make it more scientific and effective in practice. In the information age, we do not lack information. The emergence of the "Internet plus" makes the phenomenon of information explosion increasingly obvious, which will cause a few unpleasant consequences in the information life cycle of safety education (see Table 1). Therefore, it is of great significance to optimize the safety information conversion rate effectively for safety education.

4. The existing research on safety education is good at starting from a certain part but not from the perspective of the whole process of the system. 
Table 1. Phenomenon of information explosion in the information life cycle of safety education

\begin{tabular}{|c|c|c|c|}
\hline No. & Phenomenon & $\begin{array}{l}\text { Life cycle of } \\
\text { information }\end{array}$ & Unpleasant consequences \\
\hline 1 & \multirow{4}{*}{$\begin{array}{l}\text { (1) Much information is available } \\
\text { on the computer and the network, } \\
\text { and the era of information } \\
\text { explosion is the era of information } \\
\text { deficiencies. } \\
\text { (2) Lack of information } \\
\text { management or information } \\
\text { mismanagement. An increasing } \\
\text { amount of untrustworthy } \\
\text { information is available in the } \\
\text { form of media. The flooding of } \\
\text { information has caused online } \\
\text { information to increase rapidly, } \\
\text { resulting in a vicious circle. } \\
\text { (3) People often feel confused } \\
\text { about the boundaries of } \\
\text { knowledge when confronted with } \\
\text { vast amounts of ocean. }\end{array}$} & $\begin{array}{l}\text { Safety demand } \\
\text { analysis }\end{array}$ & $\begin{array}{l}\text { It is difficult to distinguish the true from the false, to grasp the key } \\
\text { points of safety education, and to make safety education decisions } \\
\text { efficiently and qualitatively. People cannot efficiently and quickly } \\
\text { obtain the needed effective information, so they always feel that they } \\
\text { do not have enough information to analyse the safety demand. }\end{array}$ \\
\hline 2 & & $\begin{array}{l}\text { Safety } \\
\text { education } \\
\text { design }\end{array}$ & $\begin{array}{l}\text { There are many optional safety education modes and much available } \\
\text { content. It is easy to produce content-stacked design schemes. } \\
\text { However, this approach is not the most practical safety education. }\end{array}$ \\
\hline 3 & & $\begin{array}{l}\text { Safety } \\
\text { education } \\
\text { implementation }\end{array}$ & $\begin{array}{l}\text { The educated are prone to receiving interference from other useless or } \\
\text { wrong information sources. The acceptance capacity is overloaded, and } \\
\text { then, redundant information blinds people and thinking becomes lazy, } \\
\text { so awareness gradually causes a loss of interest in thinking. }\end{array}$ \\
\hline 4 & & $\begin{array}{l}\text { Assessment and } \\
\text { feedback }\end{array}$ & $\begin{array}{l}\text { Information redundancy leads decision makers and participants to } \\
\text { neglect the problem and deal further with reasons for it. Therefore, } \\
\text { there are some problems in the assessment and feedback stages. }\end{array}$ \\
\hline
\end{tabular}

As science and technology develop and change environmentally and socially, research on specific scenes only has great limitations. According to the general law of information dissemination, the establishment of the best mode of the production, acquisition, transformation and storage of safety education information is conducive to guiding safety behaviours from an overall perspective.

\section{The context of IFSE}

According to the above analysis and assessment, the thinking mode based on information flow is suitable for safety education in practice. IFSE can be created by introducing advanced teaching, cognitive science and information theories into safety education. In proposing a new perspective called IFSE, three basic questions are addressed, as follows.

\subsection{What is IFSE?}

Safety education refers to the complex learning activities aimed at regulating the safety behaviours of the educated. Based on the definition of behaviour in sociology and psychology, safety behaviour refers to implicit (such as safety awareness, safety attitude, etc.) and explicit safety behaviours (such as safety skills, safety management, etc.) produced by human beings under the stimulation of internal and external environments.

From the perspective of content, IFSE refers to the process of safety information flow and the changes in the safety education system and the dynamic process of transforming the safety demand into the safety behaviour of the educated. IFSE aims to improve the efficiency of safety education in transforming safety information into safety behaviour. IFSE enhances the effectiveness of safety education activities (including the design, implementation and evaluation processes) by analysing safety demand; setting reasonable safety education objectives; selecting the appropriate safety teaching content; using scientific methods of information dissemination; developing appropriate review and assessment criteria and obtaining effective feedback, which includes accurate and reliable information support for the demands, decisions, dissemination, cognition and assessment of safety education by using policy, data, facts and case studies.

In short, IFSE can be defined as rationally utilizing information resources, including safety- and educationrelated information, in the dynamic process of the safety education system. Obviously, compared with the existing research perspectives of safety education, IFSE is more realistic and scientific because of the following five main advantages:

1. The basis of IFSE is safety demand. From its basic concept and practice, IFSE generally concerns safety demand instead of simply accumulating safety knowledge. Combining existing safety education policies, IFSE requires educational implementers or managers to conduct a demand analysis from a large amount of information to select the most useful information to facilitate the next steps, namely, the safety education design and implementation processes to solve specific safety education problems.

2. IFSE pays attention to the details and the overall system development of safety education. Therefore, from a macro-perspective, the design of safety education conforms to safety education policy, safety demand and other safety information foundations, and teaching objectives would be considered. At the micro-level, the safety education content and methods would be matched.

3. The mode of IFSE is to use advanced information technology to carry out the most effective safety education, to maximize the transformation of safety knowledge into safety behaviour, and to find the 
most effective means of dissemination and cognition for safety education. The prior knowledge of safety science and the information cognition ability of the educated would be considered.

4. The practicality of IFSE is emphasized. Aimed at the training of complex safety cognitive skills, safety behaviours are regarded as an integral task in the situation. The implementation of safety education activities is based on actual demand analyses and appropriate information technologies. In addition, according to different organizations and circumstances, IFSE proffers a solution that is in line with the actual situation.

5. Improving the information feedback mechanism is introduced for safety education. The mode of IFSE and the safety information conversion rate are the main gauges for the safety education assessment. Participants and third-party assessment institutions are important components of the feedback mechanism. In addition, the safety education scheme can be adjusted in real time according to the emergence of new events, especially changes of research objects or the occurrence of accidents.

\subsection{What is new about it?}

The safety education process includes many influent factors, such as information distortion and interference. Therefore, it is not invariant, and feedback is key to im- proving the quality of safety education activities and the conversion rate of safety information. IFSE challenges the design principles, implementation methods and assessment feedback mechanisms of safety education. Based on the information flow, the demand analysis and design method of safety education are continuously improved, and a system assessment feedback mechanism is established for the transformation of safety information into safety behaviour. In brief, information flow theory provides a new principle for the existing methodology of safety education to improve the conversion rate of safety information on the premise of optimizing safety teaching content. Table 2 lists the main differences between the current research perspective of safety education and IFSE according to some literature (Le et al., 2015; Wang et al., 2018; Zhang et al., 2017; Limberg \& Sundin, 2006; Naidoo et al., 2010; R. Kaufman \& J. D. Kaufman, 2008).

\subsection{What is its core?}

According to the definition of information flow, its purpose is to timely and reliably disseminate and respond to information based on the main demand and to improve the information transformation efficiency of the system. Therefore, the core of IFSE should be the chain process of safety information, namely, dissemination, cognition, transformation and feedback. Analysing the framework model, the basic elements and implementation steps of IFSE are its essence, as well as solving the difficulties in

Table 2. Main differences between the current research perspective of safety education and that of IFSE

\begin{tabular}{|c|c|}
\hline The current research perspective of safety education & The perspective of IFSE \\
\hline $\begin{array}{l}\text { Overreliance on the existing policies, rules, regulations } \\
\text { and teaching programs of safety education because of rigid } \\
\text { thinking. }\end{array}$ & $\begin{array}{l}\text { Existing safety policies are the basis but not the only source of } \\
\text { information. At the same time, pay attention to the collection of } \\
\text { safety management information. }\end{array}$ \\
\hline Insufficient attention to safety demand analyses. & Safety demand analysis is the foundation and key of IFSE. \\
\hline Incomplete and unsystematic information collection. & $\begin{array}{l}\text { Systematically and comprehensively collect the information } \\
\text { required by the safety education. }\end{array}$ \\
\hline $\begin{array}{l}\text { Focus only on the analysis of the objective safety demand of the } \\
\text { organization (industry). }\end{array}$ & $\begin{array}{l}\text { Combine personal safety demand and organization (industry) } \\
\text { demand analyses. }\end{array}$ \\
\hline $\begin{array}{l}\text { Emphasis on the macro-design and neglect of the micro-design } \\
\text { of safety education. }\end{array}$ & $\begin{array}{l}\text { Take the macro-design of safety education, such as safety } \\
\text { objectives, and pay attention to the micro-design of safety } \\
\text { education. }\end{array}$ \\
\hline $\begin{array}{l}\text { The choice of technology and form is more extreme, either } \\
\text { following the rules or simply pursuing new technology. }\end{array}$ & $\begin{array}{l}\text { Safety education form and technology are auxiliary means of } \\
\text { safety education not the focus of the research. The choice of } \\
\text { technology and form is based on content. }\end{array}$ \\
\hline $\begin{array}{l}\text { The adoption of new technology is regarded as a new safety } \\
\text { education method, while the adaptation and construction of } \\
\text { safety education content are ignored. }\end{array}$ & $\begin{array}{l}\text { Strengthen the construction of safety education content and } \\
\text { match it with new technology. }\end{array}$ \\
\hline $\begin{array}{l}\text { Many implementations of safety education remain aimed at } \\
\text { completing organizational tasks or legal provisions rather than } \\
\text { improving safety behaviours and awareness. }\end{array}$ & $\begin{array}{l}\text { Take the transformation of safety information into safety } \\
\text { behaviour as the fundamental purpose. }\end{array}$ \\
\hline $\begin{array}{l}\text { Lack of assessment and acceptance of safety education } \\
\text { methods, vague assessment indicators (such as classroom tests) } \\
\text { and lack of practical inspection methods. }\end{array}$ & $\begin{array}{l}\text { Carry out a systematic review and acceptance of safety education, } \\
\text { and use the conversion rate of safety information as an important } \\
\text { index of the safety education assessment. }\end{array}$ \\
\hline $\begin{array}{l}\text { The problem feedback is not timely or in place, and there is } \\
\text { a lack of systematic development to improve the root cause } \\
\text { (demand analysis and safety education design) of the existing } \\
\text { problems. }\end{array}$ & $\begin{array}{l}\text { According to the feedback, improve and develop the safety } \\
\text { education system from the foundation. }\end{array}$ \\
\hline
\end{tabular}


the process of safety education practice and improving the efficiency of the transformation of safety information into safety behaviour.

\subsubsection{The framework model of IFSE}

In Educational Informatics, information runs through the entire educational system and can be divided into the following information types: educational content, educational control, educational scientific research, educational management and educational social. This paper mainly discusses the theory of information transmission in the process of safety education and the principle of receiving and processing safety information by the educated. Therefore, the education content and education control information are the bases of constructing the framework model, that is, the combination of safety information and educational methods as well as the construction of the feedback system.

To a certain extent, any model needs to be systematic and structural. Meanwhile, the safety theoretical model needs to cover the goals, knowledge, procedures, and rules (Huang et al., 2016). Therefore, when building a model, the structure and relationship between the elements of the system need to be considered. According to the lifecycle of safety education, particularly its current difficulties and problems, the normal operation and development of safety education activity requires the support of the following basic elements: safety demand, safety information, educational method, participants, noise, feedback and environment. The framework model of IFSE (see Figure 1) can be generalized.

\subsubsection{The fundamental elements of IFSE}

According to the above framework model of IFSE, its five fundamental elements can be proposed as follows:

1. Safety demand. Safety demand refers to obtaining comprehensive and effective information by systematically and repeatedly collecting, analysing, evaluating and screening subjective and objective safety demand. Subjective safety demand refers to the existing safety habits and sense of the educated. Objective safety demand refers to system safety management data, risk assessment results, national policy documents, industry standards, and accidents or major accidents within a certain time range. The result of a safety demand analysis is to be accurate and reliable, which has important practical value

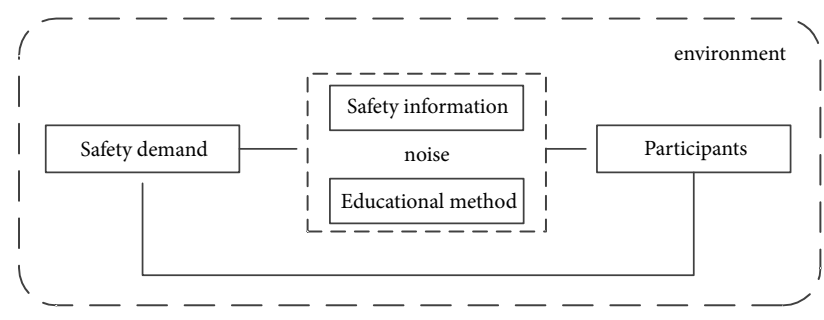

Figure 1. Framework model of IFSE in the practice of safety education, especially in the formulation of safety education objectives and the selection of teaching content and methods.

2. Safety information. Safety information refers to the safety content that can be spread and recognized. Broadly speaking, it runs through the whole process of the safety education system, including safety demand information, safety education design information, safety teaching content information, safety education assessment and feedback information, which is the bridge between the IFSE elements. Narrowly, safety information is the specific content of safety teaching and the core of safety education.

3. Educational method. Safety educational methods involve software and hardware. Software refers to the written provisions of teaching methods, information technology, relevant laws, regulations and standards. Hardware refers to ensuring the normal safety education activities of hardware infrastructure and auxiliary services. The reasonable combination of safety information and educational method in the safety education system is key to improving the conversion rate of safety education.

4. Participants. Participants include the educator and the educated. The educator, who has a clear purpose and mission in safety education, aims to deliver safety information. According to different circumstances, the educators correct, guide and promote individuals as well as receive information feedback for relearning to enhance the teaching level and perfect safety information. The educated - who have different targets, backgrounds, foundations, difficulties, and rethinking and relearning abilities - aim to obtain safety information to enhance knowledge, skills, behaviours and consciousness.

5. Environment. Environment includes many factors such as organizational safety climate, safety culture, information culture, infrastructure, hardware device, natural environment, economic environment, political environment and technical conditions. Obviously, the first three elements are closely related to the implementation of safety education. If they are neglected, the consequences may undermine the overall success of IFSE in obtaining important safety information.

Noise refers to the redundant information and bad transmission methods encountered in the process of safety education. Given the length of this paper, noise is not discussed in detail; it will be discussed in later papers.

In summary, the above elements are indispensable. Only by combining them effectively can a scientific and feasible safety education be made for achieving best practices. According to the comprehensiveness of the information elements, we derive 9 safety education elements (see Table 3) that are conducive to improving the macromanagement level of safety education and compensating for possible omissions. 
Table 3. Expanding the elements analysis of safety education

\begin{tabular}{|c|c|c|}
\hline Elements & $\begin{array}{l}\text { Expanding } \\
\text { elements }\end{array}$ & Connotation \\
\hline \multirow{2}{*}{$\begin{array}{l}\text { Safety } \\
\text { demand } \\
\text { and safety } \\
\text { information }\end{array}$} & WHAT & $\begin{array}{l}\text { Refers to the information of the safety teaching content based on the transformation of the safety } \\
\text { demand. Under the guidance of elaboration theory, the safety teaching content is designed in outline } \\
\text { form and in detail to realize a reasonable and effective organization. }\end{array}$ \\
\hline & $\begin{array}{l}\text { HOW } \\
\text { MUCH }\end{array}$ & $\begin{array}{l}\text { Under the guidance of component display theory, the behaviour level and content type of the safety } \\
\text { education are established based on the safety demand in different fields and specific scenarios. }\end{array}$ \\
\hline \multirow{3}{*}{ Environment } & WHERE & $\begin{array}{l}\text { According to the demand of the safety education, the designers should consider whether the } \\
\text { environment is outdoor or indoor and whether the classroom scene is real or virtual. }\end{array}$ \\
\hline & WHEN & $\begin{array}{l}\text { Time for the safety education and the range of time. (Such as after an accident, period of frequent } \\
\text { accidents, daily training, etc.). }\end{array}$ \\
\hline & WHY & $\begin{array}{l}\text { For occupational safety skills, daily safety demand, safety knowledge reserve, safety habits cultivation, } \\
\text { safety thinking exercises, etc. }\end{array}$ \\
\hline \multirow{2}{*}{$\begin{array}{l}\text { Educational } \\
\text { method }\end{array}$} & $\begin{array}{l}\text { HOW } \\
\text { (software) }\end{array}$ & $\begin{array}{l}\text { Written rules for teaching methods, teaching plans, laws and regulations. In particular, the } \\
\text { assessment feedback mechanism, which is key to improving the conversion rate of the safety } \\
\text { information. }\end{array}$ \\
\hline & $\begin{array}{l}\text { HOW } \\
\text { (hardware) }\end{array}$ & $\begin{array}{l}\text { Teaching buildings, tools, media and other resources or auxiliary services. Hardware facilities ensure } \\
\text { teaching activities proceed in an orderly way, and such facilities can be extended to virtual reality } \\
\text { and other aspects. }\end{array}$ \\
\hline \multirow[t]{2}{*}{ Participants } & $\begin{array}{l}\text { WHO } \\
\text { (educator) }\end{array}$ & $\begin{array}{l}\text { The educators have a clear purpose and mission for the safety education and participate in designing } \\
\text { the details of the safety education programs and delivering the safety information. Specifically, as the } \\
\text { educated change or offer feedback, the environment changes, and society progresses, the educators } \\
\text { should constantly strengthen their ability to relearn. }\end{array}$ \\
\hline & $\begin{array}{l}\text { WHO } \\
\text { (educated) }\end{array}$ & $\begin{array}{l}\text { The main purpose of the educated is to receive the safety information and improve their safety } \\
\text { behaviours. The educated have different learning purposes, foundations, difficulties, and reflection } \\
\text { and relearning abilities. }\end{array}$ \\
\hline
\end{tabular}

\section{The implementation steps of IFSE}

The implementation steps of IFSE are presented in Figure 2 .

\subsection{Safety problem}

The emergence and frequency of safety problems are the main reasons and bases for safety education. For example, for new employees of an enterprise who are not familiar with the working environment and have weak safety knowledge, safety education should be carried out systematically. For a sudden accident, the public awareness and ability of employees to investigate the potential safety hazards of the post should be strengthened, and the ability of employees to escape and render first aid should be improved to improve the team's organized accident response and emergency rescue capability. For frequent natural disasters, improve the disaster prevention, response and escape skills of the people in the area according to different disaster types and frequency areas, and improve the emergency response capability of the organization. For public safety problems in the social environment, we should start with basic education and improve public safety awareness and skills from a young age. For the shortage of safety management talent in high-risk industries, safety engineering and other related specialties are established in the higher education system as well as relevant training institutions and professional certificate assessment mechanisms to provide the requisite talent for society.

In this step, the relevant departments and organizations of safety education, within the scope of their own management, confirm the actual safety problems they face, clearly define the boundaries of the safety problems, and solve problems from the perspective of problems. Based on this approach, safety education is no longer a task-based activity but a means of safety management to solve specific problems so the educated can feel deeply the significance of safety education to help safety education develop well from the perspectives of systematic and human factors.

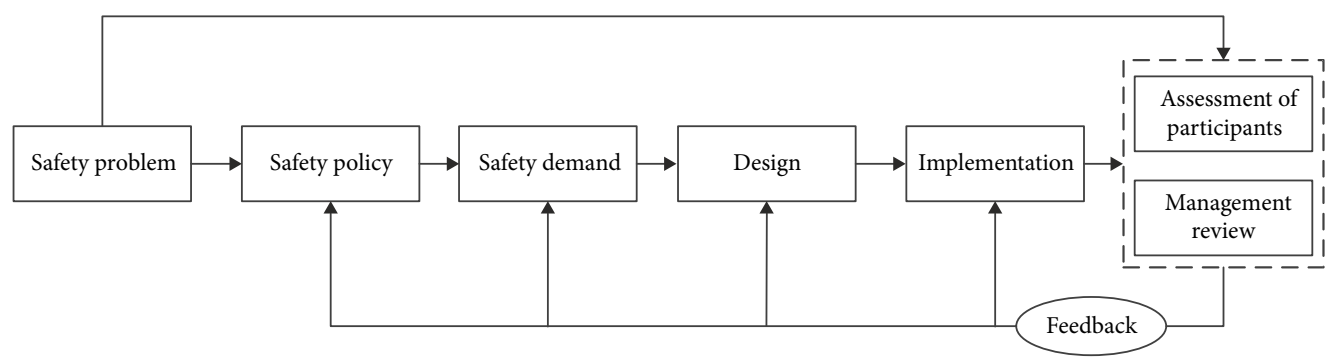

Figure 2. Implementation steps of IFSE 


\subsection{Safety policy}

From the perspective of IFSE, safety problems are the starting point of safety education and the basis for creating safety policies. Safety policies provide the legal basis for and overall design of safety education. At present, most safety education is based only on the provisions of the safety policy, which causes the safety education to be too rigid. This concept been explained in detail, and the explanation will not be repeated here. Safety policy information is the documented information that guides safety education in a macro-sense. To avoid rigidity in safety education, safety policies should not be too detailed and should be guided by a large framework.

In this step, the relevant laws, regulations and rules (such as safety production, fire protection, road traffic safety, and mine safety laws as well as other documents at different levels or in different fields) are used to devise the demand for the teaching hours and content of the safety education in the practice. The minimum time requirement of safety education and the main compulsory content scope of safety education should be defined. Combined with the actual safety problems defined in the first step, the time distribution for the safety education and its specific content are preliminarily analysed and studied.

\subsection{Safety demand}

Safety demand is the basis for avoiding the rigidity of thinking caused by excessive reliance on safety policies and related regulations. For different occasions, organizations or individuals, the purposes of safety demand analysis can be achieved by analysing the daily safety management data - including unsafe behaviour data under specific scenarios, safety hazards and safety risk data, safety management omission data and behaviour data under vir- tual reality technology scenarios, etc. - as well as conducting on-site investigations. The data are analysed, which is people-oriented, comprehensive, objective and subjective from the perspective of safety demand. At the same time, the learners' cultural level, educational acceptance ability, existing safety literacy and other personal circumstances can be included in the analysis.

Information related to the safety demand can be obtained by using databases, search engines, reference books, field research and scientific research results considering the multidimensional demand of safety sense, safety knowledge, safety skills and system safety management in specific scenarios.

\subsection{Design}

The collection, analysis, assessment and storage of relevant safety information in the pre work laid a solid foundation for the design of the safety education. In practice, the reliability, rationality and practicability of the information mentioned above can be determined first. Then, the framework of safety education should be constructed to ensure that the safety demand of the educated will be met. Finally, the scheme design of the safety education should be carried out from the two aspects of content and mode to maximize the transformation of the safety demand into safety knowledge.

The framework diagram of the safety education design based on IFSE (see Figure 3) is constructed based on the expanding elements of safety education, which has certain guiding significance in practice. Safety education includes macro-design and micro-design, and neither exist independently of the other. The macro-design guides the micro-design, and vice versa. Their conceptual connotations are depicted as follows, in Table 4.

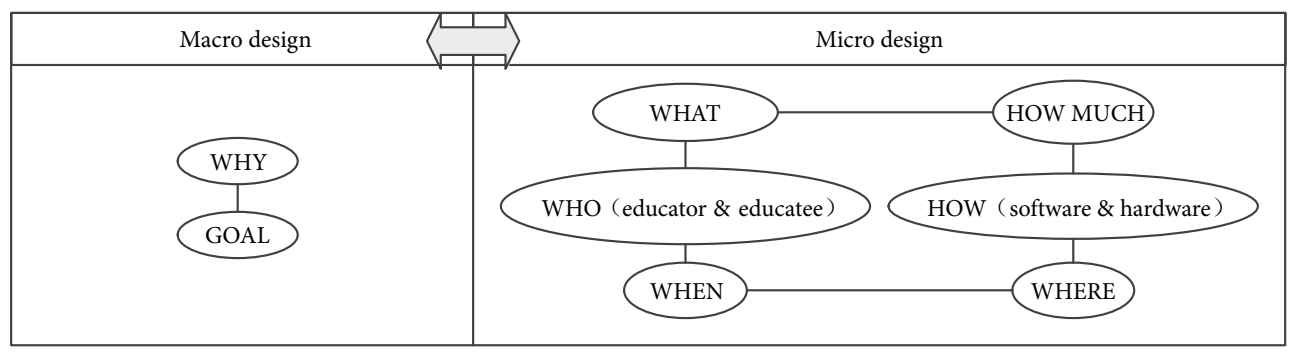

Figure 3. Framework diagram of the safety education design based on IFSE

Table 4. Macro-analysis and micro-analysis of the safety education design

\begin{tabular}{|c|l|}
\hline Perspectives & \multicolumn{1}{c|}{ Content } \\
\hline Macro & $\begin{array}{l}\text { Starting from the macro-analysis of the safety education design ensures the establishment of result-oriented safety } \\
\text { education objectives to ensure the orderly conduct of safety education activities and to emphasize the integrity } \\
\text { of the system. Doing so should involve the safety education system, framework and teaching goals as well as } \\
\text { management, policy and strategy. Elaboration theory is the strategy and method of the macro-design. }\end{array}$ \\
\hline Micro & $\begin{array}{l}\text { Starting from the micro-analysis, safety education design emphasizes the specific manifestations of each particular } \\
\text { course, including the process-oriented safety teaching objectives and motivation stimulator. Component display } \\
\text { theory is the strategy and method of the micro-design. }\end{array}$ \\
\hline
\end{tabular}




\subsection{Implementation}

From the perspective of the macro-system, the implementation process of the safety education is its core process, which is essentially the process of the transmission and cognition of safety information. As teaching and differentiating different degrees of safety demand progress in the actual situation, the progress should be adjusted in terms of time and the commitment to improve the conversion rate effectively in practice. The complete implementation process based on IFSE can be proposed, and it consists of much fundamental information content (see Figure 4), namely, the preprocessing, dissemination, perception and cognition, and feedback of the participants. These processes will have many influencing factors (see Table 5), a detailed explanation of which follows:

1. The process of the information processing of educators may have some problems, such as the educators do not know enough about the safety information or do not have the ability to extract and organize it.

2. In the process of the information dissemination, the aspects of information carriers, information channels and information stimulation may have some problems, such as the limitations of language expression or improper media designs.
3. The lack of perceptual and cognitive abilities on the part of the educated will make it difficult to obtain effective safety information. The lack of understanding and memory abilities may influence the abilities of safety knowledge storage and conversion to practical operation.

4. The feedback process may have some problems, such as the educated not being good at finding problems or having communication barriers in their expression abilities or the educators not being good at accepting opinions.

5. The specific implementation of safety education is not necessarily in line with its initial design. In addition, the micro-design may be inconsistent with the macro-design, such as a change in the teaching site or an adjustment in the teaching sequence and content, which shows the overall dynamic and expandable nature of the safety education.

Starting from the micro-individual level, safety education is a chain reaction process of safety information processing in fact. Therefore, the process model is constructed for the information processing and utilization of IFSE centred on the educated (see Figure 5).

Table 5. Factors analysis of the safety education implementation from the perspective of the macro-system

\begin{tabular}{|l|l|l|}
\hline \multirow{5}{*}{ Safety education } \\
implementation & The educators & $\begin{array}{l}\text { The dissemination of the safety education information centres on the educators. It mainly } \\
\text { includes the ability of the educators to collect, extract and organize safety information. }\end{array}$ \\
\cline { 2 - 3 } & $\begin{array}{l}\text { Safety } \\
\text { information } \\
\text { dissemination }\end{array}$ & $\begin{array}{l}\text { The dissemination of the safety education information centres on the educated. It mainly } \\
\text { includes the ability of the educated to perceive, recognize and dispose of the safety } \\
\text { information. }\end{array}$ \\
\cline { 2 - 3 } & $\begin{array}{l}\text { The information dissemination emphasizes the transmission process of the safety } \\
\text { information in the safety education system, including information carriers, information } \\
\text { channels and information stimulation. }\end{array}$ \\
\hline & $\begin{array}{l}\text { Safety } \\
\text { information } \\
\text { cognition }\end{array}$ & $\begin{array}{l}\text { A process in which the educated actively construct, restructure and improve their safety } \\
\text { cognition based on the existing cognitive structure to change external motivation (safety } \\
\text { needs) into intrinsic motivation (safety demand). It emphasizes the initiative of the educated } \\
\text { and constructs and improves the safety cognitive structure from the aspects of the safety } \\
\text { attitude, the safety knowledge and safety skills. }\end{array}$ \\
\hline
\end{tabular}

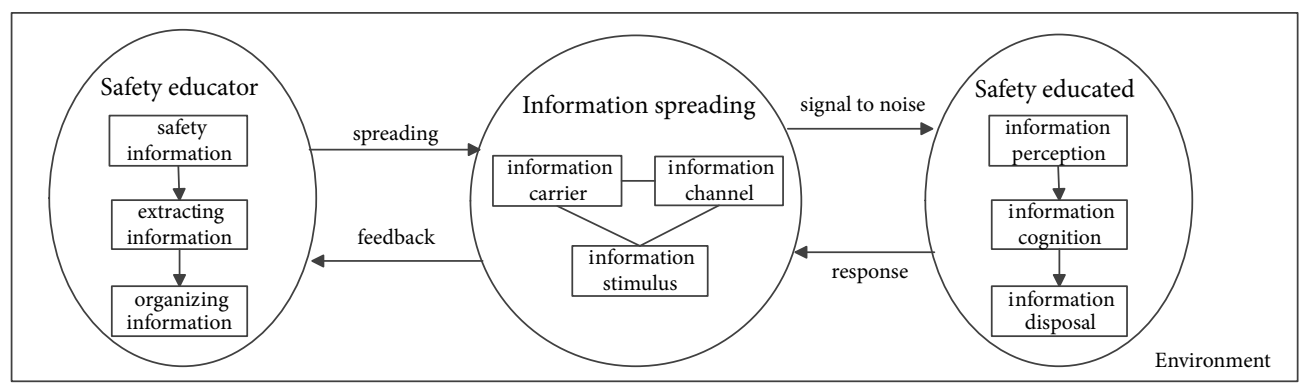

Figure 4. Implementation process of safety education

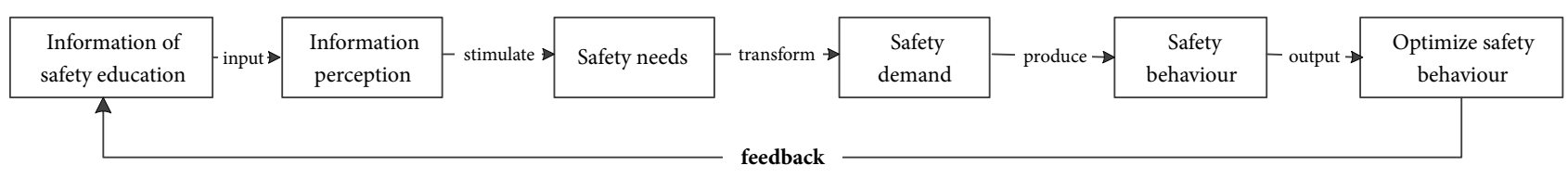

Figure 5. Process model for the information processing and utilization of IFSE centred on the educated 
This model fully covers the process of the safety information processing and utilization by the educated, namely, the safety education information is inputted, the safety education information perceived and memorized by the educated stimulates the safety needs, safety needs are transformed into safety demands, the safety demands of the educated promote their safety-related behaviours, and the safety education information used by the educated can optimize their safety behaviours. In addition, the safety needs refer to external motivation, while the safety demand refers to intrinsic motivation. The following four points can be applied in practice:

1. The educated input the safety education information through sight and hearing, and store the information in memory. This process is the initial stage of the subject's perception of safety information, during which enhancing the stimulation in sense and perception can enhance the comprehension and memory of the safety information. For example, using visualization and virtual reality technologies can comprehensively mobilize perception and deepen memory.

2. The safety education information perceived and memorized by the educated stimulates the safety needs of the educated and transforms their safety needs into their safety demands. According to their own demands and interests, the educated will choose, recognize and memorize the safety information, and some important safety information will not be accepted due to the preference of the educated. Therefore, the assessment, punishment and incentive mechanisms are introduced.

3. The safety demand of the educated promotes their safety-related behaviours, such as safety education information memory and organization as well as information utilization. On the basis of receiving and recognizing safety information, the educated can form a state of self-restraint and personal commitment.

4. The safety education information used by the educated can optimize their safety behaviours. According to the learned safety information, the educated regulate their own behaviour, change their own sense, form good safety habits and create a positive impact on others.

\subsection{Assessment and review}

The multi-angle assessment of participants and the management review are effective measures for encouraging the safety education to continually improve, and they include relearning processes, including pre-, real-time and final effect assessments. The assessments are mainly made by the participants, and the reviews are mainly made by managers and third-party organizations.

In practice, it includes three steps, namely, preparation, assessment and review, and result processing (see Figure 6). The preparations aim to establish the evaluation system according to the evaluation principles and purposes, and the assessments and reviews should be carried out by the educators, the educated, management and third-party institutions. Then, the corresponding measures should be taken according to the assessment results.

Finally, safety education-related personnel should learn from the experience and repair any weak links in the safety education system. Management reviews and assessments by participants are based on the safety demand, safety implementation and safety education conversion rate. From the perspective of macro-system management and policy designation, aiming at the safety demand, the performance of the safety education implementation process and the safety education conversion rate are the objects of the assessments, and scientific safety education assessment results are obtained.

\subsection{Feedback}

Information feedback emphasizes that the process of the acceptance and response of the educated to the safety information, including the problems existing in the process of perception, cognition and disposal as well as the attitudes towards the safety information.

If necessary, safety teaching adjustments or macro-policy modifications should be made based on the feedback from the assessment and review. Combined with the safety problems to be solved, the information closed-loop improves the effectiveness of the safety education, provides evidence for the formulation of safety policies, provides ideas for the design of the safety education, and provides improvement suggestions for the implementation of the safety education.

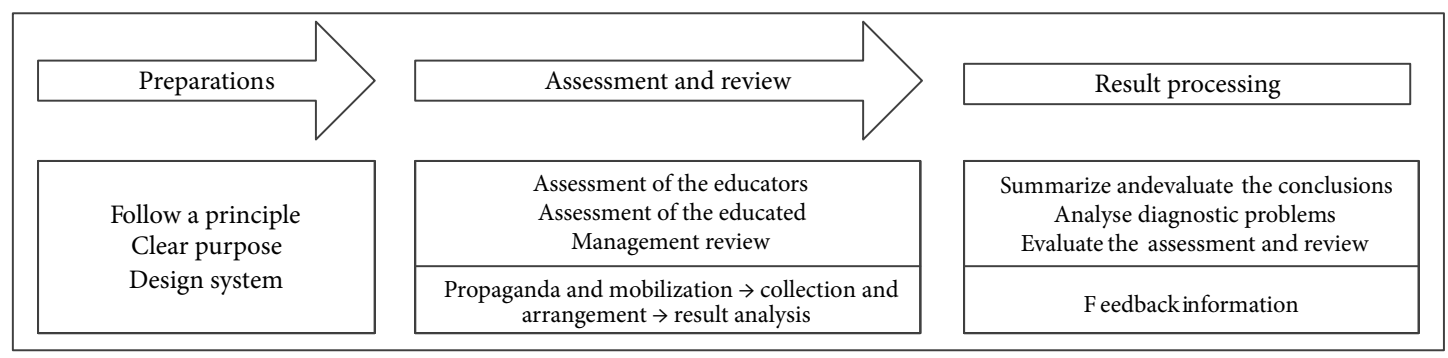

Figure 6. Process model for the assessment and review of the safety education 
The implementation of safety education is a complete closed loop safety information dissemination process from the educators to the educated. In the time dimension, safety information moves in a sequence from the educators to the educated with feedback information then given from the educated to the educators; however, safety information dissemination centred on the educator and the educated does not exist independently. They promote each other, and the information dissemination and feedback are carried out alternately (Gao et al., 2017). In practice, the IFSE is a chain effect resulting from a series of events. To improve the overall quality and efficiency of safety education, taking the transaction of turning safety information into safety behaviour as the research object, the process model of the information processing and utilization of IFSE centred on the educated is established and analysed.

\subsection{The significance of IFSE in practice}

In practice, the significance of IFSE in safety education is following:

1. In the research stage of safety education, IFSE advocates using the existing achievements in the field of safety and useful information to support the theoretical research and social practice of safety education. For instance, safety science has made progress in the aspects of safety demand analysis, safety information management and human factor accidents in recent years. Making full use of these research results can analyze the specific situation of enterprise safety management vulnerabilities and people's unsafe behaviour in the system, rather than just follow the book.

2. According to the application of information theory in the field of education, information theory is also applicable in safety education, that is, pay attention to safety knowledge as the dissemination process of information, and effectively combine the content and method of safety education, rather than simply pursuing technological innovation in this era of rapid development of technology. For example, the introduction of accident cases or the promotion of safety skills, the use of video playback or virtual reality experience means, the safety effect will be effectively improved, but the elaboration of a safety concept, in the form of icon or text.

3. IFSE studies the whole life cycle of safety education from a systematic perspective. In practice, in addition to implementing the process of safety education research and design based on effective information, it also pays attention to the information feedback after the implementation of safety education, including the educators, the educated and other relevant personnel. This kind of feedback information will act as effective information in the research of safety education and in the design process.

\section{Example application of safety education from the perspective of IFSE}

Metal and nonmetal mines are part of a high-risk industry that is one of the key regulatory industries. According to the completed work, from the perspective of IFSE, this paper carries out a safety education design for new employees of metal and nonmetal underground mines before they go to work. In the traditional design scheme, classroom safety education is used, and apprentice follow master workers carry out the safety education in practice. On this basis, this paper adds virtual reality safety training to solve the existing problems of mine safety education.

1. Preliminary preparation. From the perspective of safety problems and demands, the macro-perspective, the mine is a high-risk industry that experiences frequent accidents and great losses afterwards, so its safety issues deserve attention. From the perspective of practice, Chinese miners often have low levels of education and a limited ability to recognize and accept safety knowledge. On the basis of learning certain textual knowledge and operational procedures, educators should strengthen the multidimensional audio-visual learning mode to stimulate perception and cognition and add active and participatory project-oriented learning content to deepen memory and improve the operational level. From the perspective of risk, inexperienced miners or visitors are unfamiliar with the mine environment. Through virtual reality, they can reproduce the real scene, experience situations close to those found in reality, restore the scene to the maximum extent without risk, and experience the accident and hidden dangers from a first-person perspective. Regarding the safety policy, the regulations for the implementation of the mine safety law of the People's Republic of China clearly state that new underground workers should receive not less than 72 class hours of safety education and training. After passing the examination, they must work for 4 months under the leadership of workers with safety work experience, and then they can work independently after passing the examination again.

2. Safety content and form design (see Figure 7). From a macro-perspective, this paper summarizes the time allocation, content system, implementation methods, examination methods and assessment methods of safety education. The goal is to improve the safety knowledge, skills, awareness and attitudes of the educated. In general, the goal is to improve the safety behaviour of the educated and to strengthen the safety status of the system. The micro-perspective is based on systematic safety knowledge, operation regulations learning, and passing the written test results. The micro-perspective takes as its research point strengthening the safety training before entering the well, according to the common unsafe 
behaviours, typical safety hazards and past events of a mine in Yunnan Province, China. Thus, virtual reality technology is adopted to construct the module, namely, preparation before entering the mine and experience the underground environment and typical safety hazards (Liang et al., 2019; Taylor, 1999). The entire training process is intended to improve the safety behaviour of the educated in their daily work, strengthen their psychological endurance, calm down in case a dangerous experience occurs and take correct and effective self-rescue measures.

3. The implementation of virtual reality safety training. The virtual reality scenes are shown in Figure 8. Among them, Figure 8a shows the check of whether the wearing of personal protective equipment meets the requirements before entering the well, such as wearing the safety helmet correctly, fastening sleeves and carrying lighting tools for normal work. Figure $8 \mathrm{~b}$ shows the check of each other's state and personal protective equipment and the check of whether the other party's mental state is suitable for entering the well. Entering the well after drinking is strictly prohibited. Figure $8 \mathrm{c}$ shows the gaining of familiarity with the underground situation under the guidance of an NPC and the introduction of the facilities and equipment such as the refuge chamber. Figures $8 \mathrm{~d}$,
$8 \mathrm{e}$ and $8 \mathrm{f}$ show the risk perceptions and accident experiences in the operational process of the mine, including the roof falling, a water inrush and an object strike. These three types of accidents are also common in this investigation mine, so they are the main training contents for the mine. In addition to the prompt information in the virtual reality scene, the language prompt for educators is also necessary.

4. Assessment and feedback. From the perspective of the participants, the examination results of the educated are the visual embodiment of the safety education effect. Through the surveys and conversations, the educated evaluate the difficulty of the safety education activity, the learning content, the closeness of the learning progress to the actual work and the implementation method. The educators can give suggestions for improving the safety education form according to the learning progress and examination results. From the perspective of the manager, the assessment is carried out from the aspects of the safety education system, the hardware configuration, the teaching staff, results, etc., and professional suggestions are given. The above assessment is maintained in the form of documents and fed back in the safety demand analysis, design and implementation stage of safety education.

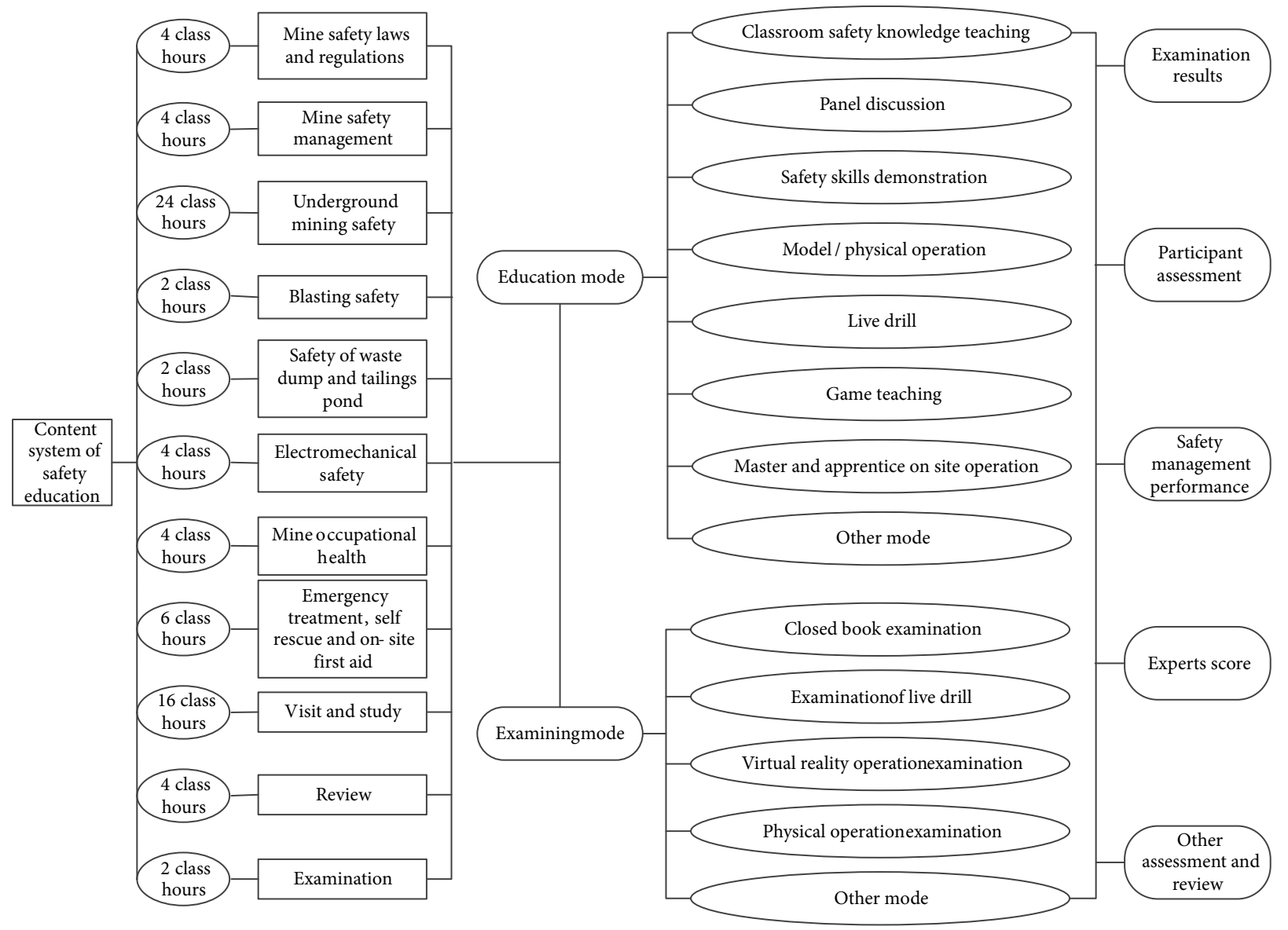

Figure 7. Macro-design of the safety education for employees in metal and nonmetal mines 


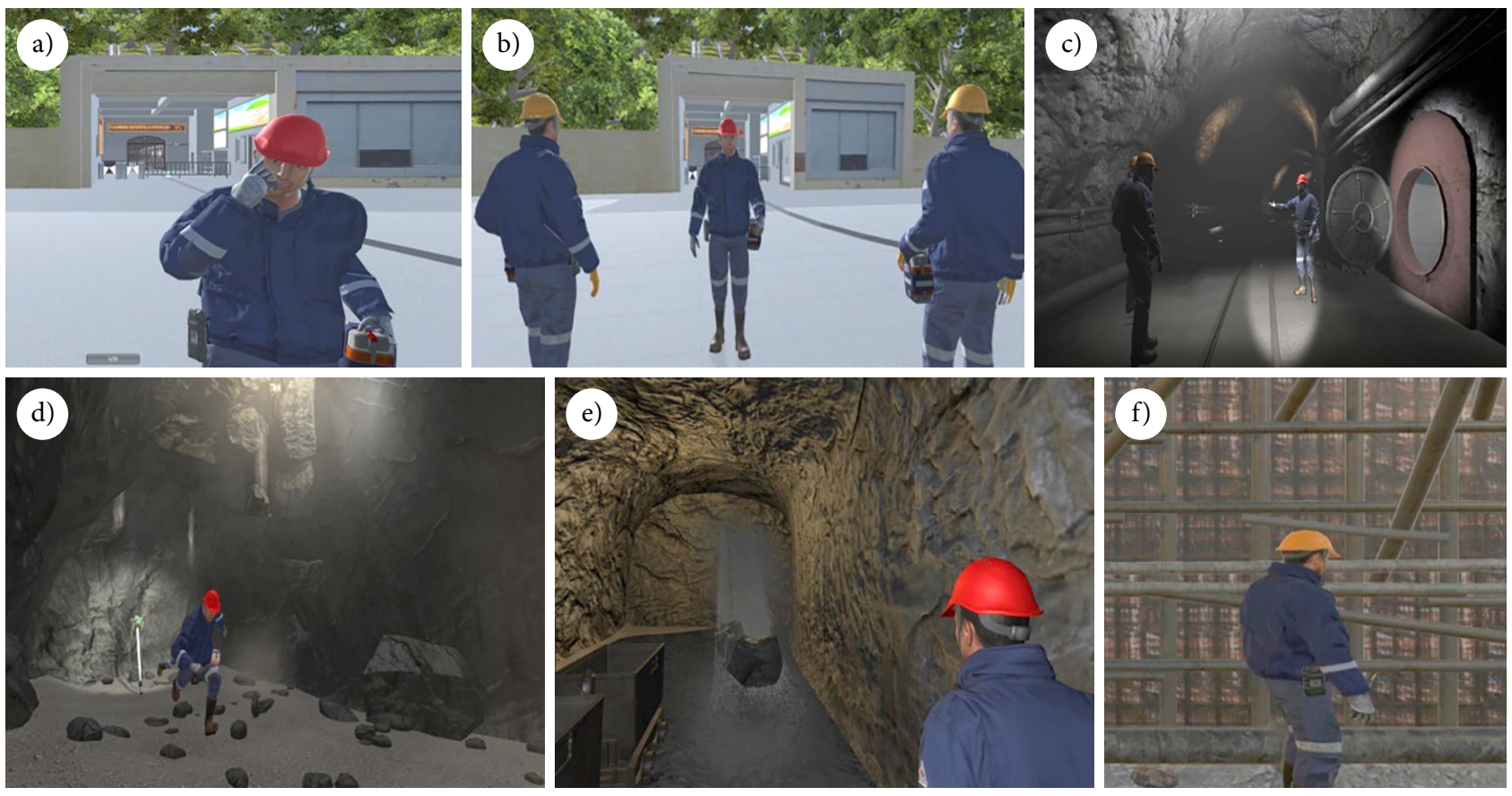

Figure 8. Interface screenshots of the virtual reality safety education before entering the mine

\section{Future directions}

The determinants and technology upgrading of IFSE are not be detailed in this study. The author hopes to provide a starting point for safety education and safety management scholars and practitioners to begin research in this field. Please join us in making IFSE a reality. To promote the application of informatics in safety education and make information practice more effective, some urgent problems to be solved in practice include ways of mining, collecting, processing, and utilizing information as well as ways of evaluating the effectiveness of safety education according to such information. In addition to on-the-spot investigations, the use of virtual reality technology to participate in the information collection process of the safety education laboratory should be studied in the future to improve the current situation in which safety education information and data are lacking.

\section{Conclusions}

In conclusion, the phrase "information-based" is a basic research object and buzzword in many fields, such as management, psychology, pedagogy, communication, and behavioural and cognitive sciences. Researchers are increasingly aware that reliable information sources are essential for macro-decision-making and micro-practice. Therefore, safety education managers and actual participants should adapt to this information-based era, and it is necessary and important to understand and utilize information actively.

IFSE is a new perspective for realizing safety education in practice, and the framework model of IFSE provides rigorous theoretical knowledge. IFSE starts from the objective safety problems and considers the safety demand.
It has a more practical role in solving the safety education problems in the information age. It can promote the effective combination of safety education content and safety education form, and improve the effect of safety education. Through the cooperation with the mine in Yunnan, some achievements have been made.

In this paper, first, a systematic review was carried out of existing safety education methods to discover their shortcomings. Second, inspired by the concept of information-flow-based, a new and effective perspective was proposed, IFSE, for teaching the practice of safety education. Finally, the basic questions of IFSE were analysed in detail, including its definition and core as well as its implementation steps and application. The information-based age drives safety managers to enhance their IFSE abilities so they can achieve the safety goals of safety education. Before the proposal of IFSE, it was perhaps more difficult for safety professionals to make effective safety decisions because necessary safety-related information was lacking. Furthermore, in the field of safety education, it will be of great significance to carry out studies on IFSE in the future.

In the future, we will continue to carry out in-depth practical research on safety education based on IFSE model in the field of mine and public safety, and deeply study the application of advanced information technology in safety education under the theoretical support of the IFSE model.

\section{Acknowledgements}

This study is supported by The Fundamental Research Funds Project for the Central South University (No. 2019zzts309). 


\section{References}

Catino, M., \& Patriotta, G. (2013). Learning from errors: Cognition, emotions and safety culture in the Italian air force. Organization Studies, 34(4), 437-467.

https://doi.org/10.1177/0170840612467156

Chaudhry, P. E., Chaudhry, S., \& Reese, R. (2011). Developing a model for enterprise information systems security. Journal of Academic Research in Economics, 3(3), 243-252.

Gao, K. X., Wu, C., \& Wang, B. (2017). Construction of general model of safety education based on information spreading. Journal of Information, 36(12), 132-137.

Glendon, A. I., \& Litherland, D. K. (2001). Safety climate factors, group differences and safety behaviour in road construction. Safety Science, 39(3), 157-188.

https://doi.org/10.1016/S0925-7535(01)00006-6

Gore, B. F. (2002). Human performance cognitive-behavioral modeling: A benefit for occupational safety. International Journal of Occupational Safety and Ergonomics, 8(3), 339-351. https://doi.org/10.1080/10803548.2002.11076534

Han, S. U., \& Lee, S. H. (2013). A vision-based motion capture and recognition framework for behavior-based safety management. Automation in Construction, 35(11), 131-141. https://doi.org/10.1016/j.autcon.2013.05.001

Heinrich, W. H. (1980). Industrial accident prevention: A safety management approach (5th ed.). McGraw-Hill Companies.

Huang, L., Wu, C., \& Jia, N. (2016). Study on methodology of safety theoretical model construction. China Safety Science Journal, 26(12), 1-6.

Kaufman, R., \& Kaufman, J. D. (2008). What should high-risk operations evaluate relative to safety and safety training. Performance Improvement Quarterly, 5, 16-24.

https://doi.org/10.1111/j.1937-8327.1992.tb00553.x

Kostopoulou, O. (2006). From cognition to the system: developing a multilevel taxonomy of patient safety in general practice. Ergonomics, 49(5-6), 486-502.

https://doi.org/10.1080/00140130600569038

Le, Q. T., Pedro, A., Lim, C. R., Park, H. T., Park, C. S., \& Kim, H. K. (2015). A Framework for using mobile based virtual reality and augmented reality for experiential construction safety education. International Journal of Engineering Education, 31(3), 713-725.

Lei, Y., Wu, C., Feng, Y. S., \& Wang, B. (2019). Optimization of multi-level safety information cognition (SIC): A new approach to reducing the systematic safety risk. Reliability Engineering \& System Safety, 190, 106497. https://doi.org/10.1016/j.ress.2019.106497

Li, H., Lu, M., Hsu, S. C., Gray, M., \& Huang, T. (2015). Proactive behavior-based safety management for construction safety improvement. Safety Science, 75, 107-117. https://doi.org/10.1016/j.ssci.2015.01.013

Liang, Z., Zhou, K., \& Gao, K. (2019). Development of virtual reality serious game for underground rock-related hazards safety training. IEEE Access, 7, 118639-118649. https://doi.org/10.1109/ACCESS.2019.2934990

Limberg, L., \& Sundin, O. (2006). Teaching information seeking: relating information literacy education to theories of information behavior. Information Research, 12(1), 904-918.

Liu, J., \& Song, X. (2014). Countermeasures of mine safety management based on behavior safety mode. Procedia Engineering, 84, 144-150. https://doi.org/10.1016/j.proeng.2014.10.420

Mcsween, T. E. (1995). The values-based safety process: Improving your safety culture with a behavioral approach. Journal of Organizational Behavior Management, 19(3), 115-119.
Misovich, S. J., Martinez, T., Fisher, J. D., Bryan, A., \& Catapano, N. (2006). Predicting breast self-examination: A test of the information-motivation-behavioral skills model. Journal of Applied Social Psychology, 33(4), 775-790.

https://doi.org/10.1111/j.1559-1816.2003.tb01924.x

Mitropoulos, P., Cupido, G., \& Namboodiri, M. (2009). Cognitive approach to construction safety: Task demand-capability model. Journal of Construction Engineering and Management, 135(9), 881-889.

https://doi.org/10.1061/(ASCE)CO.1943-7862.0000060

Mosleh, A., \& Chang, Y. (2004). Model-based human reliability analysis: Prospects and requirements. Reliability Engineering \& System Safety, 83(2), 241-253.

https://doi.org/10.1016/j.ress.2003.09.014

Naidoo, S., London, L., Rother, H.-A., Burdorf, A., Naidoo, R. N., \& Kromhout, H. (2010). Pesticide safety training and practices in women working in small-scale agriculture in South Africa. Occupational \& Environmental Medicine, 67(12), 823828. https://doi.org/10.1136/oem.2010.055863

Njenga, K., \& Brown, I. (2012). Conceptualizing improvisation in information systems security. European Journal of Information Systems, 21(6), 592-607.

https://doi.org/10.1057/ejis.2012.3

Sklet, S. (2004). Comparison of some selected methods for accident investigation. Journal of Hazardous Materials, 111(1), 29-37. https://doi.org/10.1016/j.jhazmat.2004.02.005

Songkhla, T. N., Ismail, M. H. S., Biak, D. R. B. A., Bolong, J., \& Syafiie, S. (2018). Safety behavior and incident experience of worker in gas stations of Suratthani Province, Thailand. Journal of Computational and Theoretical Nanoscience, 24(1), 485-488. https://doi.org/10.1166/asl.2018.12046

Taylor, Z. (1999). Values, theories and methods in social work education. International Social Work, 42, 309-318. https://doi.org/10.1177/002087289904200305

Wang, B., Wu, C., Shi, B., \& Huang, L. (2017). Evidence-based safety (EBS) management: A new approach to teaching the practice of safety management (SM). Journal of Safety Research, 63, 21-28. https://doi.org/10.1016/j.jsr.2017.08.012

Wang, X., Xing, Y., Luo, L., \& Yu, R. (2018). Evaluating the effectiveness of behavior-based safety education methods for commercial vehicle drivers. Accident Analysis and Prevention, 117, 114-120. https://doi.org/10.1016/j.aap.2018.04.008

Zhang, K., Suo, J., Chen, J., Liu, X., \& Gao, L. (2017). Design and implementation of fire safety education system on campus based on virtual reality technology. In 2017 Federated Conference on Computer Science and Information Systems (FedCSIS), Prague, Czech Republic. https://doi.org/10.15439/2017F376

Zhong, X. R. (2013). Construction safety accident prevention research based on $3 \mathrm{E}$ principle. Applied Mechanics \& Materials, 353-356, 2867-2871.

https://doi.org/10.4028/www.scientific.net/amm.353-356.2867

Zhou, Q., Fang, D., \& Wang, X. (2008). A method to identify strategies for the improvement of human safety behavior by considering safety climate and personal experience. Safety Science, 46(10), 1406-1419.

https://doi.org/10.1016/j.ssci.2007.10.005

Zohar, D., \& Luria, G. (2003). The use of supervisory practices as leverage to improve safety behavior: a cross-level intervention model. Journal of Safety Research, 34(5), 567-577. https://doi.org/10.1016/j.jsr.2003.05.006 